\title{
The case for Chronotherapy in COVID-19 induced Acute Respiratory Distress Syndrome (ARDS).
}

\author{
Faleh Tamimi ${ }^{1}$, Mohammad Abusamak ${ }^{1}$, Bindu Akkanti ${ }^{2}$, Zheng Chen ${ }^{3}$, Seung-Hee Yoo ${ }^{3}$, \\ and Harry Karmouty Quintana ${ }^{2}$ \\ ${ }^{1}$ McGill University \\ ${ }^{2}$ UTHealth \\ ${ }^{3}$ University of Texas Health Science Center at Houston
}

April 28, 2020

\begin{abstract}
COVID-19, the disease resulting from infection by a novel coronavirus: SARS-Cov2 that has rapidly spread since November 2019 leading to a global pandemic. SARS-Cov2 has infected over 2.8 million people and caused over 180,000 deaths worldwide. Although most cases are mild, a subset of patients develop a severe and atypical presentation of Acute Respiratory Distress Syndrome (ARDS) that is characterised by a cytokine release storm (CRS). Paradoxically, treatment with anti-inflammatory agents and immune regulators has been associated with worsening of ARDS. We hypothesize that the intrinsic circadian clock of the lung and the immune system may regulate individual components of CRS and thus chronotherapy may be used to effectively manage ARDS in COVID-19 patients.
\end{abstract}

\begin{abstract}
:
COVID-19, the disease resulting from infection by a novel coronavirus: SARS-Cov2 that has rapidly spread since November 2019 leading to a global pandemic. SARS-Cov2 has infected over 2.8 million people and caused over 180,000 deaths worldwide. Although most cases are mild, a subset of patients develop a severe and atypical presentation of Acute Respiratory Distress Syndrome (ARDS) that is characterised by a cytokine release storm (CRS). Paradoxically, treatment with anti-inflammatory agents and immune regulators has been associated with worsening of ARDS. We hypothesize that the intrinsic circadian clock of the lung and the immune system may regulate individual components of CRS and thus chronotherapy may be used to effectively manage ARDS in COVID-19 patients.
\end{abstract}

Since December 2019, SARS-Cov2 has spread rapidly leading to a global pandemic of COVID-19 (Guo et al., 2020). Although COVID-19 is mild in the majority of cases, a subset of patients quickly develop acute respiratory distress syndrome (ARDS), a clinical presentation of acute lung injury (ALI), that leads to respiratory failure requiring mechanical ventilation (Fung, Yuen, Ye, Chan \& Jin, 2020). This unprecedented crisis is equal only in magnitude to the 1918 influenza pandemic (Taubenberger \& Morens, 2006). Regrettably, despite important medical and technological advancements since then, our approach to treating patients with acute lung injury following influenza or SARS-Cov2 infection remain palliative at best, with no proven pharmacological therapies (Mehta, McAuley, Brown, Sanchez, Tattersall \& Manson, 2020).

A central challenge for the development of therapies that target ARDS is the myriad of pro-inflammatory mediators that are released during ARDS (Conti et al., 2020). This response in COVID-19-induced ARDS has been termed as a cytokine release storm (CRS) (Mehta, McAuley, Brown, Sanchez, Tattersall \& Manson, 2020; Ruan, Yang, Wang, Jiang \& Song, 2020). The CRS seen in severe cases of COVID-19 include high numbers neutrophils and low levels of lymphocytes, as well as elevated serum levels of IL-1 $\beta$, IL-2, IL-6, 
IL-8, IL-9, IL-10, IL-17, G-CSF, GM-CSF, IFN $\gamma$, TNF $\alpha$, IP10, and MCP1 (Huang et al., 2020; Ruan, Yang, Wang, Jiang \& Song, 2020). Thus, understanding the mechanisms that modulate the release of these pro-inflammatory mediators in ALI is paramount to developing effective strategies to treat ARDS.

There is an outstanding paradox that COVID-19 causes a CRS that is associated with increased lethality. Yet, reports suggest that anti-inflammatory drugs such as ibuprofen could aggravate the progression of disease. Further, recent studies in respiratory infections have shown that while anti-inflammatory agents could alleviate symptoms, they can also promote increased viral shedding (Walsh et al., 2016). Even though this possibility has not been confirmed with COVID-19, it is very plausible that this is the reason why NSAIDS could be detrimental. In this sense, ideal management of COVID-19 would entail a reduction of harmful inflammatory mediators that damage the host but maintain expression of key mediators that target the virus.

An emerging venue of therapeutic development impinges on the circadian clock, the biological timer that has been shown to control the rhythmic expression and release of many cytokines in inflammatory settings (Labrecque \& Cermakian, 2015; Thompson, Walmsley \& Whyte, 2014). However, despite the known effects of the circadian clock in lung diseases such as asthma (Clark, 1987), how the circadian clock influences the progression of ALI remains largely unknown.

Studying the circadian rhythm of lung injury secondary to ventilation therapy (Ventilator induced lung injury, VILI) is a current concern for COVID-19. Circadian rhythm disruption was seen in a rat model of VILI with high and low tidal volumes by studying the expression of Bmal1, clock, Per2 and REV-ERB $\alpha$ mRNA expression. REV-ERB $\alpha$ was found to have an important role in VILI and inflammation. That is, circadian rhythm disorder in inflammation response may be a novel pathogenesis of VILI.(Li, Wang, Hu \& Tan, 2013) Club cells have been also found to have a role in lungs circadian rhythm. Selective ablation of these cells resulted in the loss of circadian rhythm in lung slices, further demonstrating the importance of this cell type in maintaining pulmonary circadian rhythm in one murine and human lung tissue study (Gibbs et al., 2009) .

The immune system displays circadian rhythms, for instance at the beginning of daily activity there is increased expression of pro-inflammatory mediators such as interleukin(IL)-1ß, IL-6, IL-12,TLR9 and TLR4, CCL2, CXCL1, CCL5, as well as macrophage and leukocyte activity, which leads to potential damage in injured tissues. By contrast, anti-inflammatory mediators and other growth or angiogenesis factors, such as the vascular endothelial growth factor (VEGF), peak during the resting phase (Curtis, Bellet, Sassone-Corsi \& O'Neill, 2014; Koyanagi et al., 2003; Liu et al., 2006; Nakamura et al., 2016; Scheiermann, Gibbs, Ince \& Loudon, 2018; Vgontzas, Bixler, Lin, Prolo, Trakada \& Chrousos, 2005). Moreover, both CD8 and CD4 T cells cytotoxic activity against viral antigens reach the highest levels during the resting phase (Bollinger et al., 2011; Nobis, Laramée, Kervezee, De Sousa, Labrecque \& Cermakian, 2019) while the cytotoxic activity of natural killer (NK) cells was most severe at the beginning of the active part of the day (Logan et al., 2012).

The lungs also have an intrinsic circadian clock which plays a key role in inflammation and leukocyte migration in the lungs, as well as in many lung diseases including viral pneumonia (Nosal, Ehlers \& Haspel, 2019; Sundar, Yao, Sellix \& Rahman, 2015).

Circadian rhythms in viral respiratory illness have been so far examined in mice for parainfluenza and influenza A viruses (IAV), which cause bronchiolitis, and pneumonia in humans respectively. With either virus, acute inflammatory responses, but not the peak viral load, vary with the time of inoculation in wildtype mice (Ehlers et al., 2018; Sengupta et al., 2019). Similarly, deletion of the clock gene Bmal1 worsens acute lung injury and lung inflammation in response to parainfluenza or IAV, suggesting that circadian clocks may play a role (immunologic or otherwise) in the resolution of viral pneumonia. Additionally, there is strong evidence from animal models that the circadian regulation within the lung is important in the likelihood of developing chronic lung disease such as pulmonary fibrosis in the aftermath of the infections.

The time of the day in which a viral infection occurs affects the survival. For instance infections at the 
beginning of the activity phase are more fatal than infections that occur at the beginning of the resting phase (Sengupta et al., 2019). Evidence indicates an important role of the circadian rhythm of NK cells underlying this temporal pattern.

Due to circadian variations of the immune system and the lungs, the effect of immune modulators and antiinflammatory agents on the activity of cells and cytokines in injured tissues also depend on the time of the day in which these medications are taken (Al-Waeli et al., 2020). It is plausible that a proper circadian timing of anti-inflammatory drugs (chronotherapy) can target the detrimental inflammatory cascade in COVID19 patients without interfering with the fight of the immune system against the virus. For instance, the circadian time of drug administration will differentially affect various cytokines involved in viral immunity and COVID-19, including among others IP10, IL-1b, IL-4, IL-8, IL-10, TCR, INF- $\alpha$, CIITA, TNF- $\alpha$, and TLR as well as the activity of T cells (CD8), NK cells, and B cells (Al-Waeli et al., 2020; Canan et al., 2014).

Based on the known circadian peak (point of culmination of an oscillatory function) and circadian through (lowest value of an oscillatory function) for known detrimental (Table 1 ) or beneficial (Table 2 ) inflammatory mediators identified in COVID-19 patients, treatment could be optimized for chronotherapy. Hereby, adjusting the timing of the day in which the medications are given to result in highest drug levels at the time point when detrimental inflammatory mediators reach their Peak (Figure 1). This would mean that afternoon is the preferred time window for drug administration whereas nighttime intake should be avoided.

Table 1. Detrimental inflammatory mediators in the cytokine release storm (CRS) in COVID19 (RED).

\begin{tabular}{|c|c|c|c|}
\hline & PEAK & Trough & Reference \\
\hline IL-1 $\beta$ & Bedtime & Early morning & $\begin{array}{l}\text { (Einhorn, Majeska, } \\
\text { Rush, Levine \& } \\
\text { Horowitz, 1995) }\end{array}$ \\
\hline IL-2 & $1200 \mathrm{~h}$ & & $\begin{array}{l}\text { (Young, Matthews, } \\
\text { Kanabrocki, Sothern, } \\
\text { Roitman-Johnson \& } \\
\text { Scheving, 1995) }\end{array}$ \\
\hline IL-6 & $\begin{array}{l}\text { First Peak } 1900 \text { h Second } \\
\text { Peak 0500h }\end{array}$ & & $\begin{array}{l}\text { (Vgontzas, Bixler, Lin, } \\
\text { Prolo, Trakada \& } \\
\text { Chrousos, 2005) }\end{array}$ \\
\hline IL-8 & $\begin{array}{l}\text { First peak } 1000 \mathrm{~h} \\
\text { Second peak } 2100 \mathrm{~h}\end{array}$ & & (Rahman et al., 2015) \\
\hline IL-10* & $\begin{array}{l}\text { First peak } 0730 \mathrm{~h} \\
\text { Second peak } 1930 \mathrm{~h}\end{array}$ & & $\begin{array}{l}\text { (Young, Matthews, } \\
\text { Kanabrocki, Sothern, } \\
\text { Roitman-Johnson \& } \\
\text { Scheving, 1995) }\end{array}$ \\
\hline G-CSF & $2200 \mathrm{~h}$ & & $\begin{array}{l}\text { (Jilma, Hergovich, } \\
\text { Stohlawetz, Eichler, } \\
\text { Bauer \& Wagner, 1999) }\end{array}$ \\
\hline GM-CSF & $\begin{array}{l}\text { First peak } 1330 \mathrm{~h} \text { Second } \\
\text { peak } 1930 \mathrm{~h}-2330 \mathrm{~h}\end{array}$ & & $\begin{array}{l}\text { (Young, Matthews, } \\
\text { Kanabrocki, Sothern, } \\
\text { Roitman-Johnson \& } \\
\text { Scheving, 1995) (Rahman } \\
\text { et al., 2015; Young, } \\
\text { Matthews, Kanabrocki, } \\
\text { Sothern, } \\
\text { Roitman-Johnson \& } \\
\text { Scheving, 1995) }\end{array}$ \\
\hline
\end{tabular}




\begin{tabular}{|c|c|c|}
\hline & Trough & Reference \\
\hline $\mathrm{TNF} \alpha$ & $\begin{array}{l}\text { First Peak } 0730 \mathrm{~h} \text { Second } \\
\text { Peak } 1200 \mathrm{~h}-1330 \mathrm{~h}\end{array}$ & $\begin{array}{l}\text { (Young, Matthews, } \\
\text { Kanabrocki, Sothern, } \\
\text { Roitman-Johnson \& } \\
\text { Scheving, 1995) (Young, } \\
\text { Matthews, Kanabrocki, } \\
\text { Sothern, } \\
\text { Roitman-Johnson \& } \\
\text { Scheving, 1995; Zabel, } \\
\text { Linnemann \& Schlaak, } \\
\text { 1993) }\end{array}$ \\
\hline MCP1 & $0200 \mathrm{~h}$ & (Rahman et al., 2015) \\
\hline
\end{tabular}

*involved both in the "cytokine storm" and in the anti-viral response

Table 2. Beneficial inflammatory mediators in the cytokine release storm (CRS) in COVID19 (Green).

\begin{tabular}{|c|c|c|c|}
\hline & Peak & Trough & Reference \\
\hline B cells & $0200 \mathrm{~h}-0300 \mathrm{~h}$ & $1100 \mathrm{~h}$ & $\begin{array}{l}\text { (Born, Lange, Hansen, } \\
\text { Molle \& Fehm, 1997) }\end{array}$ \\
\hline $\begin{array}{l}\text { T cells: Naive, central } \\
\text { memory, effector memory } \\
\text { CD4+ and CD } 8+T \text { cells }\end{array}$ & $0200 \mathrm{~h}$ & $1400 \mathrm{~h}$ & $\begin{array}{l}\text { (Dimitrov, Benedict, } \\
\text { Heutling, Westermann, } \\
\text { Born \& Lange, 2009) }\end{array}$ \\
\hline Effector CD8+ T cells & $1400 \mathrm{~h}$ & $0200 \mathrm{~h}$ & $\begin{array}{l}\text { (Dimitrov, Benedict, } \\
\text { Heutling, Westermann, } \\
\text { Born \& Lange, 2009) }\end{array}$ \\
\hline NK cells & $1100 \mathrm{~h}-1400 \mathrm{~h}$ & $0200 \mathrm{~h}$ & $\begin{array}{l}\text { (Born, Lange, Hansen, } \\
\text { Molle \& Fehm, 1997) }\end{array}$ \\
\hline IL-10* & $\begin{array}{l}\text { First peak } 0730 \mathrm{~h} \\
\text { Second peak } 1930 \mathrm{~h}\end{array}$ & & $\begin{array}{l}\text { (Young, Matthews, } \\
\text { Kanabrocki, Sothern, } \\
\text { Roitman-Johnson \& } \\
\text { Scheving, 1995) }\end{array}$ \\
\hline $\mathrm{IFN} \gamma$ & $0000 \mathrm{~h}$ to $0300 \mathrm{~h}$ & $0800 \mathrm{~h}$ to $1100 \mathrm{~h}$ & $\begin{array}{l}\text { Petrovsky \& Harrison, } \\
\text { 1998; Petrovsky, } \\
\text { McNair \& Harrison, } \\
\text { 1998) }\end{array}$ \\
\hline
\end{tabular}

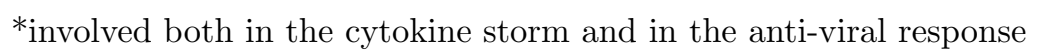

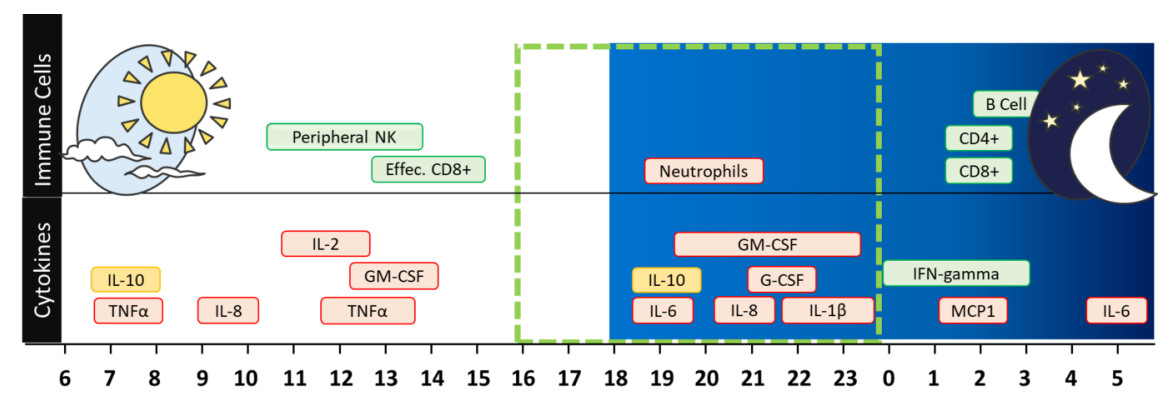


Figure 1. Diagrammatic representation highlighting the peak of cytokines and immune responses involved in the cytokine release storm (CRS) of COVID-19 . Peak detrimental inflammatory mediators (red) and beneficial adaptive immune response against viral infections (green) are shown during a $24 \mathrm{~h}$ time period. The dotted line and the red clock indicate the period between 4:00 pm and midnight in which the detrimental effects of CRS outweighs the beneficial effect of the adaptive immune response. This period of time could be the ideal target for anti-inflammatory treatments. On the other hand, the green clocks indicate the periods of anti-viral activity of the immune system, these are the periods in which anti-inflammatory therapy should be avoided.

\section{References}

Al-Waeli H, Nicolau B, Stone L, Nada LA, Gao Q, Abdallah M, et al. (2020). Chronotherapy of NonSteroidal Anti-Inflammatory Drugs May Enhance Postoperative Recovery. Scientific reports 10: 1-14.

Bollinger T, Leutz A, Leliavski A, Skrum L, Kovac J, Bonacina L, et al. (2011). Circadian clocks in mouse and human CD4+ T cells. PloS one 6.

Born J, Lange T, Hansen K, Molle M, \& Fehm HL (1997). Effects of sleep and circadian rhythm on human circulating immune cells. J Immunol 158: 4454-4464.

Canan CH, Gokhale NS, Carruthers B, Lafuse WP, Schlesinger LS, Torrelles JB, et al. (2014). Characterization of lung inflammation and its impact on macrophage function in aging. Journal of leukocyte biology 96: $473-480$.

Clark T (1987). Diurnal rhythm of asthma. Chest 91: 137S-141S.

Conti P, Ronconi G, Caraffa A, Gallenga C, Ross R, Frydas I, et al. (2020). Induction of pro-inflammatory cytokines (IL-1 and IL-6) and lung inflammation by COVID-19: anti-inflammatory strategies. Journal of biological regulators and homeostatic agents 34 .

Curtis AM, Bellet MM, Sassone-Corsi P, \& O'Neill LA (2014). Circadian clock proteins and immunity. Immunity 40: 178-186.

Dimitrov S, Benedict C, Heutling D, Westermann J, Born J, \& Lange T (2009). Cortisol and epinephrine control opposing circadian rhythms in $\mathrm{T}$ cell subsets. Blood, The Journal of the American Society of Hematology 113: 5134-5143.

Ehlers A, Xie W, Agapov E, Brown S, Steinberg D, Tidwell R, et al. (2018). BMAL1 links the circadian clock to viral airway pathology and asthma phenotypes. Mucosal immunology 11: 97-111.

Einhorn TA, Majeska RJ, Rush EB, Levine PM, \& Horowitz MC (1995). The expression of cytokine activity by fracture callus. Journal of Bone and Mineral Research 10: 1272-1281.

Fung S-Y, Yuen K-S, Ye Z-W, Chan C-P, \& Jin D-Y (2020). A tug-of-war between severe acute respiratory syndrome coronavirus 2 and host antiviral defence: lessons from other pathogenic viruses. Emerging microbes \& infections 9: 558-570.

Gibbs JE, Beesley S, Plumb J, Singh D, Farrow S, Ray DW, et al.(2009). Circadian timing in the lung; a specific role for bronchiolar epithelial cells. Endocrinology 150: 268-276.

Guo YR, Cao QD, Hong ZS, Tan YY, Chen SD, Jin HJ, et al. (2020). The origin, transmission and clinical therapies on coronavirus disease 2019 (COVID-19) outbreak - an update on the status. Military Medical Research 7: 11 .

Huang C, Wang Y, Li X, Ren L, Zhao J, Hu Y, et al. (2020). Clinical features of patients infected with 2019 novel coronavirus in Wuhan, China. The Lancet 395: 497-506.

Jilma B, Hergovich N, Stohlawetz P, Eichler HG, Bauer P, \& Wagner O (1999). Circadian variation of granulocyte colony stimulating factor levels in man. British journal of haematology 106: 368-370. 
Koyanagi S, Kuramoto Y, Nakagawa H, Aramaki H, Ohdo S, Soeda S, et al. (2003). A molecular mechanism regulating circadian expression of vascular endothelial growth factor in tumor cells. Cancer research 63: 7277-7283.

Labrecque N, \& Cermakian N (2015). Circadian Clocks in the Immune System. Journal of biological rhythms 30: $277-290$.

Li H, Wang C, Hu J, \& Tan J (2013). A study on circadian rhythm disorder of rat lung tissue caused by mechanical ventilation induced lung injury. Int Immunopharmacol: 249-254.

Liu J, Mankani G, Shi X, Meyer M, Cunningham-Runddles S, Ma X, et al. (2006). The circadian clock Period 2 gene regulates gamma interferon production of NK cells in host response to lipopolysaccharide-induced endotoxic shock. Infection and immunity 74: 4750-4756.

Logan RW, Zhang C, Murugan S, O'Connell S, Levitt D, Rosenwasser AM, et al. (2012). Chronic shift-lag alters the circadian clock of NK cells and promotes lung cancer growth in rats. The Journal of Immunology 188: 2583-2591.

Mehta P, McAuley DF, Brown M, Sanchez E, Tattersall RS, \& Manson JJ (2020). COVID-19: consider cytokine storm syndromes and immunosuppression. The Lancet.

Nakamura Y, Nakano N, Ishimaru K, Ando N, Katoh R, Suzuki-Inoue K, et al. (2016). Inhibition of IgE-mediated allergic reactions by pharmacologically targeting the circadian clock. Journal of Allergy and Clinical Immunology 137: 1226-1235.

Nobis CC, Laramée GD, Kervezee L, De Sousa DM, Labrecque N, \& Cermakian N (2019). The circadian clock of CD8 T cells modulates their early response to vaccination and the rhythmicity of related signaling pathways. Proceedings of the National Academy of Sciences 116:20077-20086.

Nosal C, Ehlers A, \& Haspel JA (2019). Why Lungs Keep Time: Circadian Rhythms and Lung Immunity. Annual Review of Physiology 82.

Petrovsky N, \& Harrison LC (1998). The chronobiology of human cytokine production. International reviews of immunology 16: 635-649.

Petrovsky N, McNair P, \& Harrison LC (1998). Diurnal rhythms of pro-inflammatory cytokines: regulation by plasma cortisol and therapeutic implications. Cytokine 10: 307-312.

Rahman SA, Castanon-Cervantes O, Scheer FA, Shea SA, Czeisler CA, Davidson AJ, et al. (2015). Endogenous circadian regulation of pro-inflammatory cytokines and chemokines in the presence of bacterial lipopolysaccharide in humans. Brain, behavior, and immunity 47:4-13.

Ruan Q, Yang K, Wang W, Jiang L, \& Song J (2020). Clinical predictors of mortality due to COVID-19 based on an analysis of data of 150 patients from Wuhan, China. Intensive care medicine: 1-3.

Scheiermann C, Gibbs J, Ince L, \& Loudon A (2018). Clocking in to immunity. Nature reviews Immunology 18: $423-437$.

Sengupta S, Tang SY, Devine JC, Anderson ST, Nayak S, Zhang SL, et al. (2019). Circadian control of lung inflammation in influenza infection. Nature communications 10: 1-13.

Sundar IK, Yao H, Sellix MT, \& Rahman I (2015). Circadian molecular clock in lung pathophysiology. American journal of physiology Lung cellular and molecular physiology 309: L1056-1075.

Taubenberger JK, \& Morens DM (2006). 1918 Influenza: the mother of all pandemics. Emerg Infect Dis 12: $15-22$.

Thompson AA, Walmsley SR, \& Whyte MK (2014). A local circadian clock calls time on lung inflammation. Nature medicine 20: 809-811. 
Vgontzas AN, Bixler EO, Lin HM, Prolo P, Trakada G, \& Chrousos GP (2005). IL-6 and its circadian secretion in humans. Neuroimmunomodulation 12: 131-140.

Walsh P, Behrens N, Chaigneau FRC, McEligot H, Agrawal K, Newman JW, et al. (2016). A randomized placebo controlled trial of ibuprofen for respiratory syncytial virus infection in a bovine model. PloS one 11.

Young MRI, Matthews JP, Kanabrocki EL, Sothern RB, Roitman-Johnson B, \& Scheving LE (1995). Circadian rhythmometry of serum interleukin-2, interleukin-10, tumor necrosis factor- $\alpha$, and granulocytemacrophage colony-stimulating factor in men. Chronobiology international 12: 19-27.

Zabel P, Linnemann K, \& Schlaak M (1993). [Circadian rhythm in cytokines]. Immun Infekt 21 Suppl 1: $38-40$.

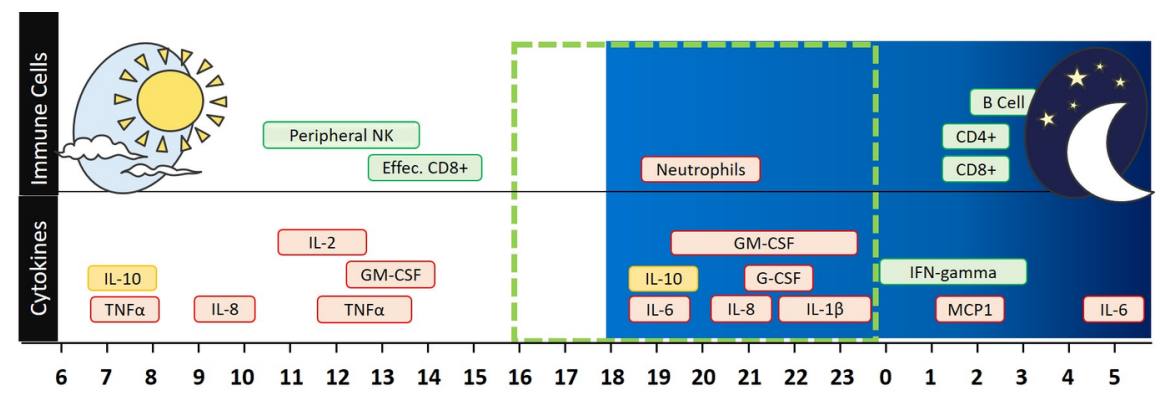

